\title{
Reseñas
}

\section{Alberto I. VARGAS, Genealogía del miedo. Un estudio antropológico de la modernidad desde Leonardo Polo. Pamplona, Universidad de Navarra, 2017, 236 p.}

La sociedad contemporánea se encuentra actualmente en una crisis individual y social, la cual ostenta diferentes manifestaciones políticas, sociales, económicas, religiosas, culturales, espirituales, con consecuencias graves que calan en lo más íntimo de la persona. Esta crisis, a la que Alberto Vargas hace referencia tomando como punto central el pensamiento del filósofo español Leonardo Polo, suele caracterizarse como una crisis antropológica, ya que se distingue porque está instalada en un ámbito universal y es propia de sociedades totalitarias, donde el carácter social personal del hombre se sobrepone al carácter personal y da lugar al anonimato o al "hombre masa".

A raíz de esta crisis inminente, Alberto Vargas nos muestra de manera grandiosa el diagnóstico respecto de sus causas, que son detalladas en su libro de la siguiente manera: "1) es desesperante [la crisis], pues no se sabe cuándo se va a salir de ella o si se podrá salir; 2) es compleja, es decir, compuesta de múltiples dimensiones, global y colectiva; 3) es íntima, pues se ha interiorizado hasta el grado de pretender identificarse con ella; 4) es fragmentaria, ya que convive con una sensación falsa de libertad, pues identifica 'situación' con 'libertad'(p. 30).

El autor, a partir de estas causas, nos centra en el análisis de esta crisis contemporánea o antropológica, pues considera que todas estas características se pueden entender como una sola, guardando una unidad, y esto porque todas se encuentran "dominadas por el miedo y la mentira y dan lugar a la pérdida de la orientación global. De ahí que se pueda afirmar que la multiplicidad de crisis responde a la manifestación de una mayor y más profunda crisis interior, estéril y sin crecimiento..." (p. 31). A partir de esto, el autor elabora su "genealogía del miedo", pero guardando su eje central en la visión antropológica del filósofo Leonardo Polo.

Es de destacar que el libro que se reseña, además de ostentar de manera sobresaliente una visión que mira a la trascendencia divina, muestra una delimitación histórica, propicia para que tanto el filósofo como el historiador

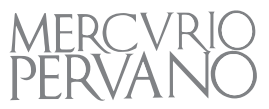


puedan diferenciar la historia del pensamiento de la de los hechos, siendo la primera no solo historia de la filosofía, sino también de la sabiduría humana. ${ }^{1}$

Así, en relación con el esquema del libro, este se ha dividido en cinco capítulos, en los que se trata primero de conceptuar la crisis antropológica o de la modernidad, para luego estudiar el miedo como su rasgo principal. Pero lo valioso no termina en la estructura del cuerpo de su investigación, sino también en el aporte bibliográfico, en razón de que divide las obras del filósofo Leonardo Polo en: a) libros, b) colaboraciones, c) artículos en revistas y d) inéditos. Para culminar luego con la bibliografía complementaria utilizada en el libro.

En su primer capítulo, denominado "Una encrucijada: La crisis de la sociedad contemporánea", el autor nos otorga la noción de 'crisis antropológica'. Esta noción la diversifica en dos ámbitos: la crisis como problema y la crisis como situación, y finaliza el capítulo con la "etiología de la crisis", en cuyo contenido nos explica las cinco ideologías que envuelven la crisis actual: cientificismo, relativismo, escepticismo, materialismo y ateísmo. En la relación con la crisis como problema, es de destacar la importancia que se da a la libertad, pues para el autor: "[l]a posibilidad de crecimiento sugiere libertad. La persona humana es fundamentalmente libre para perfeccionar perfeccionándose; es libre para crecer y, por lo tanto, existe la posibilidad libre de renunciar a ese crecimiento. Cuando ese crecimiento se detiene, o no encuentra canales o alternativas de crecimiento, podríamos decir que la persona se encuentra en una situación de crisis" (p. 13).

La misma apreciación de la libertad para la persona el autor la refleja en la sociedad, ya que considera a ambas como "sistemas abiertos y libres": "[l] a sociedad es un sistema abierto capaz de aprendizaje positivo y negativo, de crecimiento y de disminución. Solo desde este punto de vista podemos decir con justicia -como tanto se repite hoy- que estamos en una gran crisis social. Solo si admitimos que la sociedad es libre, podemos hablar de sociedad en crisis. La crisis de la cultura occidental manifiesta una crisis del hombre" (p. 14).

La crisis actual es un problema que afecta la posibilidad de crecimiento de la persona y, por ende, de la sociedad. La posibilidad de crecimiento positiva o negativa depende de la libertad de ambas, pues existe un riesgo in situ latente, toda vez que la persona puede elegir la alternativa incorrecta o reductiva, y originarse una "entropía social" degenerativa que ocasiona el "miedo a la libertad y el temor a la incertidumbre", es decir, al futuro. En sí para el autor: [e]s propio del hombre y de la sociedad tener problemas, pero es aún más propios de ellos resolverlos. En este sentido, lo radical en el hombre no son los problemas que lo aquejan, sino su solución; no es la crisis lo propio del hombre, sino el

\footnotetext{
Ignacio Falgueras Salinas, “Leonardo Polo ante la filosofía clásica y moderna”. Disponible en [http://webpersonal.uma.es/ jifalgueras/Leonardo_Polo/Leonardo_Polo/Clasica.html], con acceso el 5 de noviembre del 2018.
}

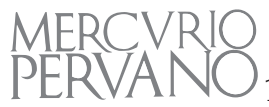


crecimiento irrestricto. Además de todo lo que se pueda decir del hombre, este es un solucionador de problemas que aborda el futuro con inventiva, abriéndolo y convirtiéndolo en una oportunidad" (p. 15).

Por su parte, la crisis como situación hace referencia al estado del hombre, en el que la historia unida a ese estado hace que la libertad humana sea histórica. Así, siguiendo el pensamiento poliano, el autor sostiene: "[la] situación se corresponde con estado y está íntimamente unida con la historia, por eso la situación de la libertad humana es histórica pero de ningún modo se agota en el nivel situacional". La historia nos proporciona los datos para profundizar en la crisis que nos aqueja hoy, la cual desde la "situación de la libertad humana" implica un conjunto de características que dejan al hombre desorientado en el mundo.

En el segundo capítulo del libro, "El miedo en el inicio de la modernidad", nos adentrarnos en los orígenes de la crisis contemporánea, para lo cual el autor se remonta al pasado, y señala: "La historia del pensamiento se concentra en tres grandes hitos históricos [...]. El primero de ellos es el periodo griego: en la primera mitad del siglo IV a.C en Atenas y bajo el liderazgo de Sócrates, Platón y Aristóteles. El segundo es el periodo medieval: en la segunda mitad del siglo XIII y el primer tercio del XIV en París, y bajo el liderazgo de Alberto Magno, Alejandro de Hales, Buenaventura, Tomás de Aquino, Eckhart, Escoto y Ockham. El tercero es el periodo idealista: de finales del siglo XVIII y principios del XIX en Berlín, bajo el liderazgo de Fichte, Hegel y Schelling" (p. 56).

Se advierte en el libro que a estas cumbres del pensamiento le suceden momentos de crisis o decadencias históricas, y citando a Polo, el autor refiere: “La primera es la griega, que tiene lugar a fines del s. V a. de Cristo a consecuencia de las Guerras del Peloponeso (432-404 a.C.). La segunda acontece en la Europa medieval del primer tercio del s. XIV y está representada por el nominalismo. La tercera ocurre en la Europa moderna a finales del s. XVIII, y se caracteriza por la quiebra de la conciencia cristiana. En la cuarta, en que nos hallamos inmersos, comenzó con lo que se suele llamar kulturkrisis" (p. 56).

De todas estas crisis, el autor se inclina por el periodo bajo medieval, el cual es el de mayor decadencia histórica y que se convierte en el momento de mayor pesimismo en la vida del hombre. Para esto la relevancia de este periodo radica en ser una crisis antropológica, producto de la unión de una crisis individual y social de la cultura cristiana. En este periodo, la serenidad es intervenida por el pensamiento aristotélico, replanteado por Alberto Magno y Tomás de Aquino, y rechazado posteriormente por Escoto y Ockham, para quienes, a juicio de Polo y asumido por Vargas, la modernidad ya está pensada en ellos. Estos filósofos medievales plantean "el miedo a Aristóteles y a la razón humana, que induce a abandonar como imposible el ideal de perfeccionamiento integral humano, a declarar utópica nuestra capacidad de Dios". 
Este libro deja sentado que la modernidad empieza a gestarse con Escoto y Ockham, y que la postura histórica, que señala que la modernidad se dio a principios del siglo XIV, no es del todo clara incluso hoy, "pues la conciencia histórica nos la oculta, y es por eso que muchos piensan que Descartes, o quizá Galileo, fue el fundador de la Edad Moderna. Tal vez lo más correcto sería decir que son ellos los que la activan, pero detrás de Descartes está Escoto" (p. 61).

Otro punto importante aducido por el autor, como correlato del miedo, es la tristeza, la cual es muy antigua, siendo desde una perspectiva filosófica fruto de la Baja Edad Media; y esto, en razón del voluntarismo de Escoto y Ockham, quienes tornan comprensible a Dios como una voluntad arbitraria, a la cual no podemos llegar. En este sentido, el camino que va de la tristeza espiritual hacia la desesperanza es corto, siendo ambas el "armazón de la genealogía del miedo en la modernidad".

El "pesimismo teoantropológico" se aborda en el libro como manifestación del miedo en la sociedad contemporánea, en el que de manera muy acertada se plantea un decurso histórico que incluye a Lutero y culmina con la crisis en la Iglesia. El autor afirma que este pesimismo aún persiste en nuestra sociedad actual, que se caracteriza por una falta de esperanza y una muerte de la intimidad personal. Así, partiendo de todo este bagaje histórico y filosófico, el autor sostiene que el miedo es "la situación en que se encuentra una sociedad a la que se le pide un esfuerzo inventivo que no está dispuesta. Es actuar con pereza, o mejor dicho, no actuar, no acometer por el esfuerzo que comporta. En definitiva, miedo a abandonarse en Dios" (p. 78). Así, desde esta perspectiva, la Iglesia también puede caer en la acidia, en la tristeza espiritual, la cual se presenta como una falta de coexistencia, y esto sucede cuando el hombre peca. Al hacerlo rompe su comunidad con Dios y se envuelve en la soledad; el hombre sencillamente se aleja de la coexistencia y se invade de desesperación.

En el tercer y cuarto capítulo se incluye el análisis del miedo en la Edad Moderna y en el gran siglo XIX. Así, en el tercero se estudia el miedo en la filosofía de Descartes y de Hobbes. Teniendo como contenido también el principio de resultado, el cual es consecuencia del pesimismo teoantropológico. Es relevante el estudio que se realiza de este principio en la medida en que, basado en la filosofía poliana, advierte las seis tesis que abarca este postulado. Ellas comprenden lo característico de la crisis antropológica o de la modernidad. Entre estas características encontramos los reduccionismos antropológicos, los cuales, a juicio del autor, responden a las siguientes preguntas: “¿Cuál es el impulso, la dotación tendencial eficaz que hay en el hombre?, y, en consecuencia, ¿cuáles son los objetivos a los que el hombre puede aspirar?"

Los reduccionismos antropológicos implican fragmentar la integridad del hombre, quien actúa mirando un solo aspecto de su vida manifestativa. Así, es resaltante cómo el libro muestra la clasificación de los reduccionismos a lo largo de la historia, desde Maquiavelo hasta Kierkegaard, y considera: "El

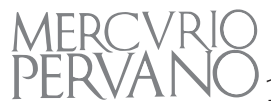


reduccionista embarca toda la vida a una sola capacidad, a una sola fuerza. Ante la incapacidad de las posturas reduccionistas de responder de modo consistente a las preguntas fundamentales de la existencia humana [el sincretismo] significa el esfuerzo por superar los inconvenientes de los reduccionismos, y en el intento de resolver se problematiza aún más si no se es capaz de sintetizar, de integrar en lo que une" (p. 119).

El futuro también es materia de este libro, en estricto la opción del futuro en el hombre ante la crisis. Así, el autor en su cuarto capítulo, denominado "Obturación: desfuturizando el futuro", parte históricamente del siglo XVIII, en el que de manera conjunta con la Revolución francesa se desata el fenómeno social conocido como el "gran miedo". Y así afirma: "Aunque deudora de la crisis del nominalismo, la Revolución francesa, es, en el pensamiento de Polo, la tercera crisis histórica de relieve".

Para el autor, el pesimismo extremo reaparece y se ingresa en la "conciencia contemporánea del porvenir". Paralelamente a este postulado, encontramos en el libro la incidencia del futurismo, la emancipación de la razón y la afirmación del yo. Todo esto nos lleva a un progreso histórico problematizado, en que el hombre moderno ha intentado "dar a luz a un hombre llamado Yo. Ha intentado darse luz a sí mismo, pero se ha desfondado en el intento y ya no sabe cómo dar de nuevo cabida a sus entrañas".

Con la finalidad de explicar este futuro desfuturizado, Alberto Vargas nos lleva desde la crisis romántica, la dialéctica de Hegel hasta el poshegelianismo en las figuras de Kierkegaard, Marx y Nietzsche. En este paso histórico, en el apartado: "La catatonía post-moderna: desesperados ante la complejidad", apreciamos ya con claridad la razón, para el autor, del desmoronamiento del hombre y del estancamiento de su energía histórica, al sostener lo siguiente:

la situación de crisis tiene su origen en un error, en una equivocación de principio: el estrechamiento de la inspiración clásica y, sobre todo, el abandono del cristianismo; en definitiva, el rechazo de la fuerza teórica de Aristóteles y de Tomás de Aquino [así] [1]a repetida elección de alternativas erróneas nos ha llevado desde la situación de la tristeza espiritual hasta la más profunda desesperación, que no siempre se manifiesta con un grito descontrolado, sino más bien a través del sinsentido, de la masificación, de la superstición, de aburrimiento, de la soledad, y también del ateísmo, la violación y el suicidio (p. 150).

En este momento (del siglo XIX para adelante) nos encontramos en una nueva versión de la crisis del nominalismo: la kulturcrisis, es decir, "en la discusión del pensamiento ilustrado", la cual, a juicio del autor, "propicia el sincretismo del psicoanálisis y marxismo, o el patetismo de Heidegger" (p. 153). La kulturcrisis difunde una cultura de masas, en la que impera el relativismo y donde el pesimismo teoantropológico está más presente que nunca; es la posmodernidad o, mejor dicho, la crisis de la modernidad. El 
hombre posmoderno - acusa el autor - "adopta una postura tímida propia del desencanto interior, y esa timidez pusilánime se refleja en la mediocridad de proyectos y en la indigencia del espíritu. Esta timidez desencantada es hoy el fruto visible de la tristeza espiritual moderna" (p. 154). Siguiendo la misma postura, en páginas posteriores y relacionándola con la conciencia crítica, el autor señala:

La postmodernidad es el período de conciencia crítica de la modernidad. La conciencia crítica es un paso necesario para la superación de la crisis. Consiste en caer en la cuenta de que estamos en crisis. La conciencia crítica significa la comprensión de la crisis como múltiple, como fragmentada, como la enfermedad en el cuerpo humano. Para superar la crisis es necesario comprenderla de modo integral, unitario [...] Los postmodernos comprenden la crisis pero sólo parcialmente, sólo conocen el apéndice, mientras que la propuesta poliana permite sintetizar, descubrir el núcleo. Las advertencias de los postmodernos no son despreciables, pues nos avisan y nos alertan, pero es preciso no detenerse en tales denuncias. (p. 178)

Como último capítulo de este libro, tenemos el $\mathrm{V}$ denominado "La enfermedad antropológica". En él encontramos la solución a la crisis contemporánea, a ese mal antropológico que aqueja nuestra sociedad actual. Para Alberto Vargas se puede comprender el error moderno de creer que el hombre no es capaz de Dios, cuando el miedo se toma como presente y no en perspectiva de futuro, y se pierde así el juego de la libertad y el futuro se obtura. Entonces ¿qué debe hacer el hombre?

La respuesta que se da en el libro es precisa. El autor maneja una única alternativa, que, siguiendo a Leonardo Polo, es "crecer", pues "[s]e resiste, se huye o se hace de recursos para crecer en el ámbito personal [...]. Desde el carácter de además no hay sitio para un miedo que haga desistir, pues si lo propio del hombre es crecer en tanto que co-existencia con Dios, los recursos disponibles son la co-actividad personal (libertad trascendental) y sobre todo la Actividad Divina".

La riqueza de este capítulo se centra en la solución al miedo contemporáneo. Ahora se debe mirar hacia la libertad trascendente. El autor, ante la complejidad de la crisis contemporánea, que se analiza en el libro, nos muestra una receta ante la enfermedad antropológica de hoy: hay que aceptar que el hombre es un ser espiritual y libre, dejar el reduccionismo materialista y aceptar al hombre en dimensiones de alcance trascendente. La crisis actual es una de carácter personal en la que el miedo y la mentira pasan a niveles más críticos: la desesperación y el ateísmo.

Así, el interés principal del libro está en que el autor, con un trasfondo antropológico, ofrece una guía a través de la historia hasta la génesis de la crisis de la sociedad actual y señala una solución que se encuentra en el hombre mismo, en su intimidad, y que se enlaza con la apertura a su Creador, a Dios.

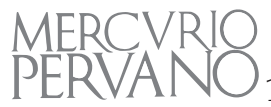




\section{Reseñas}

Esta obra es valiosa y de lectura obligada no solo para los dedicados a la filosofía y antropología, sino también para el historiador, los estudiosos de las leyes, el director de una empresa, en sí para todos. En virtud de que nos ayuda a generar una conciencia crítica de la crisis actual que nos invade y nos llena hoy de pesimismo. No hay duda de que la lectura del libro será muy provechosa, pues nos invita a un reencuentro con nuestra libertad, con nuestra coexistencia y con Dios. 